\title{
ON SOME QUANTUM APPROACHES TO BIOMOLECULAR RECOGNITION
}

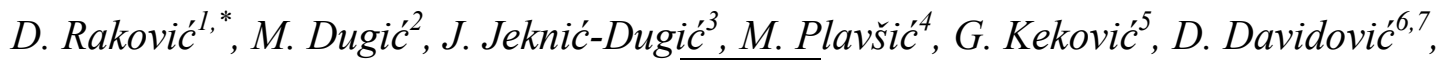

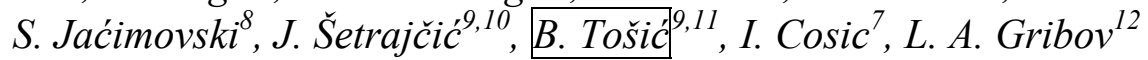 \\ ${ }^{1}$ Faculty of Electrical Engineering, University of Belgrade, Serbia \\ ${ }^{2}$ Faculty of Science, University of Kragujevac, Serbia \\ ${ }^{3}$ Faculty of Science, University of Niš, Serbia \\ ${ }^{4}$ Faculty of Technology and Metallurgy, University of Belgrade, Serbia \\ ${ }^{5}$ Biological Institute, University of Belgrade, Serbia \\ ${ }^{6}$ Vinca Institute, University of Belgrade, Serbia \\ ${ }^{7}$ School of Electrical and Computer Engineering, RMIT, Melbourne, Australia \\ ${ }^{8}$ Crime-Police Academy, Belgrade, Serbia \\ ${ }^{9}$ Faculty of Science, University of Novi Sad, Serbia \\ ${ }^{10}$ Academy of Sciences and Arts of the Republic of Srpska, Banja Luka, BiH \\ ${ }^{11}$ Vojvodina Academy of Sciences and Arts, Novi Sad, Serbia \\ ${ }^{12}$ V. I. Vernadsky Institute of Geochemistry and Analytical Chemistry, RAS, Moscow, Russia
}

\begin{abstract}
Two unresolved issues of the (semi)classically addressed problems in molecular biophysics are unreasonably long time necessary for change of biopolymer conformations and long-range directedness of selective biomolecular recognition processes - implying their essential quantum origin. In this paper, several possible quantum approaches to biomolecular recognition are considered: Theory of Non-Radiative Resonant Structural Transitions, Model of Quantum Decoherence, and Resonant Recognition Model. These approaches might be of fundamental importance in understanding underlying macroscopic quantum-holographic Hopfield-like control mechanisms of morphogenesis, and their backward influence on the expression of genes, with significant potential psychosomatic implications.
\end{abstract}

Keywords: Biomolecular Recognition, Conformational Transitions, Quantum Biophysics, Quantum Bioinformatics.

\section{INTRODUCTION}

Conformational properties of enzymes are essentially important for understanding of enzymic catalytic activity. The conformational lability of protein makes possible its specific interaction with substrates. As the substrate is (most frequently) lowmolecular, and the enzyme is (high-molecular) protein, then the substrate directly interacts with particular small part of the enzyme molecule - its active site (group and distribution of amino acid residues and cofactors (coenzymes, vitamins, metalo-organic complexes, hormones)).

In the enzyme-substrate complex (ESC) the $i$ nduced structural correspondence of the enzyme and substrate is dynamically established thus providing the optimal value of the free energy of interaction. The involved conformational transformations lead to a structural fit between the enzyme and the substrate, i.e. biomolecular recognition. The enzyme-substrate interaction is a weak chemical bond (Van der Waals, hydrogen, hydrophobic,...), which is, however, very enhanced due to hydrophobic active site of the enzyme: namely, relative dielectric permittivity $\varepsilon_{r}$ of the cavity of active site of the enzyme is much less $\left(\varepsilon_{r} \sim 3-4\right)$ compared to water environment $\left(\varepsilon_{r} \sim 81\right)$, which significantly facilitates the occurrence of electric interactions $(F \sim$ $\left.q_{1} q_{2} / 4 \pi \varepsilon_{0} \varepsilon_{r} r^{2}\right)$ between the substrate and the active site of the enzyme. Practically, electrostatic interactions within hydrophobic cavity (active site) of the enzyme provide main contribution to bioenergetics of enzymic catalysis, i.e. to reduction of the activation barrier in the ESC. The energy necessary for conformational changes of the enzyme structure is 1iberated upon binding of the substrate to the enzyme.

During enzyme-substrate interaction and formation of the ESC, the states of the electronic shells 
of the substrate and of the atomic groups of the active site of the enzyme are excited. In the ESC the energy of electronic excitation is converted to the work of displacement of atomic nuclei. Among the movements of atomic nuclei the lowest energy is demanded by low-frequency deformational vibrations and rotations around single bonds, i.e. conformational changes! Hence, for enzymic catalysis the most significant are interactions of electronic and conformational degrees of freedom - Electronic-Conformational Interactions [1].

However, two unresolved issues of the (semi) classically addressed problems in molecular biophysics are unreasonably long time necessary for change of biopolymer conformations (Levinthal paradox [2]) and long-range directedness of selective biomolecular recognition processes - implying their essential quantum origin $[3,4]$, with some quantum approaches considered further on.

\section{QUANTUM MODELS OF ELECTRONIC-CONFORMATIONAL INTERACTIONS AND BIOMOLECULAR RECOGNITION}

The quantum nature of biomolecular recognition might be supported by: (1) Theory of Non-Radiative Resonant Structural Transitions [5], through intermediate quantum-coherent superposition of the externally activated electronic-vibrational states of the participating bio-molecules; (2) Model of Quantum Decoherence [6-8], through environment-induced conformational transitions in biomolecular recognition, with possibility to consider cellular biomolecular recognition as a Hopfield-like quantumholographic associative neural network; and (3) Resonant Recognition Model (RRM) [9,10], based on findings that informational biomolecules and their targets have common RRM-frequency peak, but almost opposite phases - which will be further on elaborated in detail.

\subsection{Theory of Non-Radiative Resonant Structural Transitions}

Within the framework of standard quantumchemical Hamiltonian (including kinetic energies and Coulomb interactions of all biomolecular electrons and nuclei) and Born-Openheimer adiabatic approximation (of separated biomolecular electronic and vibrational degrees of freedom), Theory of Non-Radiative Resonant Structural Transitions [5] replaces the (quasi)classical problem of many-electron hypersurface $E_{e}\left(\phi_{e}^{(k)}\right)$, not adiabatically well-defined when traversing between two adjacent local minima, by better defined problem of two (virtually intersecting) isomeric many-electron hyper-surfaces (hyper-paraboloids) serving as potential hyper-surfaces for two vibrational (isomeric) problems, cf. Fig. 1.

In this approach, by external perturbation of the isomers, at this very intersection the conditions for electronic-vibrational non-radiative resonant transitions between the two isomers $(i, f)$ are achieved: these resonance electronic-vibrational states of two isomers are transformed from the corresponding (nonperturbed) products of electronic and vibrational wavefunctions $\left(\phi_{e}^{(i)} \phi_{v}^{(i)}, \phi_{e}^{(f)} \phi_{v}^{(f)}\right)$ into (perturbed) symmetrized superposition $\left(\phi_{e}^{(i)} \phi_{v}^{(i)} \pm \phi_{e}^{(f)} \phi_{v}^{(f)}\right) / \sqrt{ } 2$, and their (nonperturbed) energies from resonating (equal) superpositions of the ground electronic energies of corresponding minima of many-electron hypersurface and vibrational energies of higher excited states $\left(E_{e}^{(i)}+E_{v}^{(i)}=E_{e}^{(f)}+\right.$ $\left.E_{v}^{(f)}\right)$ into (perturbed) slightly split energy doublet $\left(E_{e}^{(i)}+E_{v}^{(i)}+1 / 2 \Delta E, E_{e}^{(f)}+E_{v}^{(f)}-1 / 2 \Delta E\right)$, with $\Delta E=$ $2\left(E_{e}^{(i)}+E_{v}^{(i)}\right) S_{e v}^{(i, f)}$ (where electronic-vibrational overlap integral between the two resonating isomeric states $(i, f)$ is $S_{e v}^{(i, f)}=\iint \phi_{e}^{(f)} \phi_{v}^{(f)} \phi_{e}^{(i)} * \phi_{v}^{(i)} * d V_{e} d V_{v} \approx$ $S_{v}^{(i, f)} S_{e}^{(i, f)}$, while $S_{v}^{(i, f)}$ and $S_{e}^{(i, f)}$ are corresponding overlap integrals of vibrational and electronic components). In the first approximation, the matrix element of dipole transition from $i$-th to $f$-th isomer is given by $\boldsymbol{\mu}^{(i, f)} \approx$ $\iint \phi_{e}^{(f)} \phi_{v}^{(f)}\left(\boldsymbol{\mu}_{e}+\boldsymbol{\mu}_{v}\right) \phi_{e}^{(i)} * \phi_{v}^{(i)} * d V_{e} d V_{v} \approx$ $\boldsymbol{\mu}_{e}^{(i, f)} S_{v}^{(i, f)}+\boldsymbol{\mu}_{v}^{(i, f)} S_{e}^{(i, f)}$, where $\boldsymbol{\mu}_{e}$ and $\boldsymbol{\mu}_{v}$ are corresponding electronic and nuclear components of the operator of total dipole moment. It is obvious that transition between two isomers will be allowed when components of corresponding dipole moments, $\boldsymbol{\mu}_{e}^{(i, f)}$ and $\boldsymbol{\mu}_{v}^{(i, f)}$, and overlap integrals, $S_{v}^{(i, f)}$ and $S_{e}^{(i, f)}$, do not vanish!

From the above consideration, it can be concluded that allowed transitions between isomeric states $(i, f)$ are possible only for close states with non-vanishing overlap integrals $S_{v}^{(i, f)}$ and $S_{e}^{(i, f)}$, or in cascade resonant transitions between close intermediate participating isomeric states, which might be related to non-dissipative polaron/soliton-like transport $[3,11]$.

Also, during these resonant transitions, the perturbed biomolecular system is shortly described by quantumcoherent superposition $\left(\phi_{e}^{(i)} \phi_{v}^{(i)} \pm \phi_{e}^{(f)} \phi_{v}^{(f)}\right) / \sqrt{ } 2$, before its quantum decoherence into final electronic 
state $\phi_{e}^{(f)}$ or into initial electronic state $\phi_{e}^{(i)}$ (with subsequent de-excitations into lower vibrational states).

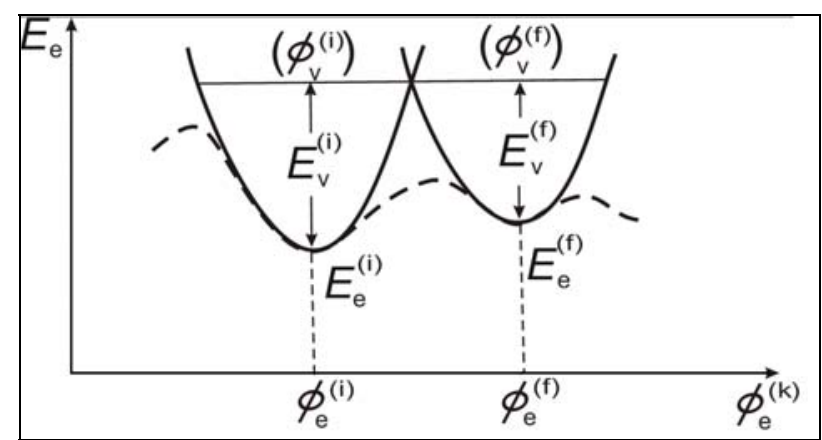

Figure 1. The (semi)classical problem of many-electron hypersurface $E_{e}\left(\phi_{e}^{(k)}\right)$ as a potential energy for adiabatically

decoupled $Q 1 D$ vibrational and conformational system (with local minima as semi-classical 'positions', i.e. many-atomic isomer configurations on many-electron hypersurface (broken line in the figure)) - not adiabatically well-defined when traversing between two adjacent local minima - is replaced in the framework of theory of non-radiative resonant transitions [5] by better defined problem of two (virtually intersecting) isomeric many-electron hypersurfaces (hyperparaboloids) serving as potential hypersurfaces for two vibrational (isomeric) problems (full line in the figure). In this approach, by external perturbation of the isomers, at this very intersection, the conditions for electronic-vibrational nonradiative resonant transitions between the two isomers (i,f) are achieved: in the first approximation, the matrix element of dipole transition from $i$-th to f-th isomer is given by $\boldsymbol{\mu}^{(i, f)} \approx$ $\boldsymbol{\mu}_{e}^{(i, f)} S_{v}^{(i, f)}+\boldsymbol{\mu}_{v}^{(i, f)} S_{e}^{(i, f)}$, and it is obvious that transition between two isomers will be allowed when components of corresponding electronic and vibrational dipole moments, $\boldsymbol{\mu}_{e}^{(i, f)}$ and $\boldsymbol{\mu}_{v}^{(i, f)}$, and electronic and vibrational overlap integrals, $S_{v}^{(i, f)}$ and $S_{e}^{(i, f)}$, do not vanish. Also, during these resonant transitions the perturbed biomolecular system is shortly described by quantum-coherent superposition $\left(\phi_{e}^{(i)} \phi_{v}^{(i)} \pm \phi_{e}^{(f)} \phi_{v}^{(f)}\right) / \sqrt{ } 2$, before its quantum decoherence into final electronic state $\phi_{e}^{(f)}$ or into initial electronic state $\phi_{e}^{(i)}$ (with subsequent de-excitations into lower vibrational states).

\subsection{Model of Quantum Decoherence}

Model of Quantum Decoherence [6-8] is in agreement with the previously described picture of short-lasting description of quantum-coherent superposition of states of the two isomers before its quantum decoherence into one of the two final isomer states. It generally allows reproduction of both existence and stability of the (stationary) ligand-proteins/target-receptors key/lock mis-matching and matching conformations, and the short time scales for the quantum-mechanical processes resulting effectively in (nonstationary) mismatching-to-matching conformational transitions in selective ligandproteins/ target-receptors key/lock biomolecular recognition processes under external (e.g. compositional/chemical, thermal, optical...) influences on the cell's complementary cytoplasmatic environment.

Dynamic modification of (many-electron) energy-state hypersurface $E_{e}\left(\phi_{e}\right)$, of the cell's quantumensemble protein/substrate biomolecular macroscopic open quantum system (through changes in operator of density of states $\left.\hat{\rho}_{e}(t)\right)$, is a natural consequence of coupled electronic-conformational processes - which implies potential possibility to consider cell's biomolecular recognition as Hopfield's quantum-holographic associative neural network. This approach assumes standard cell's local treatment of quantum ensemble of non-interacting dynamically non-coupled $N$ distinguishable quantum biomolecular proteins of the same type (and their corresponding biomolecular classes of substrates) $[3,6-8]$.

However, there is an alternative possibility of holistic cell's non-local treatment of quantum system of non-interacting dynamically coupled $N$ in-distinguishable quantum biomolecular proteins of the same type (and their corresponding biomolecular classes of substrates) $[3,8]$. Then dynamical modification of many-electron energy-state hypersurface of cell's biomolecular protein macroscopic open quantum system (and analogously their corresponding biomolecular classes of substrates), can be best represented in the formalism of second quantization, which treats all biomolecules of the same atomic configuration as in-distinguishable quantum particles which occupy different isomeric-conformational states, and considers such cell's $N$-particle protein quantum state in quantum-mechanical occupational basis which describes the number of proteins that occupy subsequently all states of complete basis set of single-particle isomeric-conformational protein states.

Both approaches provide a plausible quantumholistic picture of biological cell (while experiments will decide in favour of one of them!) - and especially phenomenologically approved quantum-holographic (fractal) coupling of various hierarchical quantum levels - from-biological cell-to-acupuncture system/consciousness [3,12]. This implies Hopfield-like quantum-holographic feedback influence of the EM field of acupuncture system on cells' conformational protein changes and genes' expression (so called macroscopic 'downward causation'), and not only reversed (microscopic 'upward causation'), with mutual quantum-informational control of onto- 
genesis/ embryogenesis and morphogenesis, starting from the first division of the fertilized cell when differentiation of the acupuncture system begins - with significant psycho-somatic and cognitive bioinformational implications $[3,8,12]$.

To be more specific, in the formalism of the second quantization - the mentioned cell's $N$-particle protein quantum state is considered in quantummechanical occupational basis (generally bosonic, because of protein-substrate integer spin due to even number of their covalent bonded electrons!), describing number of proteins which occupy complete set of single-particle protein-substrate isomeric/ conformational states: $\left|n_{0} n_{1} n_{2} \ldots\right\rangle_{e}$, with conditions $N=n_{0}+n_{1}+n_{2}+\ldots$ and $E_{S_{e}}=n_{0} E_{e}^{(0)}+n_{1} E_{e}^{(1)}+n_{2} E_{e}^{(2)}+\ldots$ (where $E_{S_{e}}$ is the many-electron energy of the total cell's $N$-particleprotein quantum state, while $E_{e}^{(0)}, E_{e}^{(1)}, E_{e}^{(2)} \ldots$ are the many-electron energies of the protein single-particle quantum isomeric/ conformational states $0,1,2, \ldots)$. The many-electron energy-state hypersurface of such protein $N$-particle-isomeric/ conformational state has a schematic representation of Fig. 2, where internal surface of every minimum is proportional to the partial energy $\left(n_{i} E_{e}^{(i)}\right)$ of the $i$-th protein single-particleisomeric/conformational state occupied by $n_{i}$ isomers of the same form $(i=0,1,2, \ldots)$, so that total energy $\left(E_{S_{k e}}\right)$ of the cell's protein $\mathrm{N}$-particle-isomeric/ conformational state is proportional to the sum of internal surfaces of the all minima of the many-electron hypersurface.

It should be noted that the inclusion of vibrational degrees of freedom (phonons) of all possible isomeric/ conformational states, requires their consideration in quantum-mechanical occupational basis (also bosonic, because of phonon's integer spin!) describing number of phonons occupying complete set of single-particle phonon states of all the proteinsubstrate isomers/ conformations:

$$
\left|n_{1}^{(0)} n_{2}^{(0)} \ldots n_{3 N-6}^{(0)} n_{1}^{(1)} n_{2}^{(1)} \ldots n_{3 N-6}^{(1)} n_{1}^{(2)} n_{2}^{(2)} \ldots n_{3 N-6}^{(2)} \ldots\right\rangle_{v}
$$

where every isomeric protein-substrate complex composed of $N_{i}$ atoms has generally $3 N_{i}-6$ vibrational degrees of freedom (phonon types), out of which every phonon state can be occupied by an unlimited number of phonons (which is characteristic of all bosons, i.e. particles of integer spin). It should be pointed out that an energy hypersurface of multi-dimensional phonon quantum state has also a schematic representation of Fig. 2, with potentially unlimited number of phonons in every single-phonon state. So, on the cellular level for every set of identical molecules, there would exist two (interacting) macroscopic quantum subsystems - first with modifying many-electron hypersurface $E_{e}\left(\phi_{e}\right)$ and second with modifying EM multi-phonon hypersurface $E_{v}\left(\phi_{v}\right)$ (where the second one might also include low-energy longrange coherent microwave Fröhlich excitations [13] created as a result of interaction of electronic and phonon isomeric subsystems, of particular significance in microwave resonance therapy (MRT) of a dynamic modification of the EM multi-phonon (and related manyelectron) acupuncture macroscopic quantum subsystem).

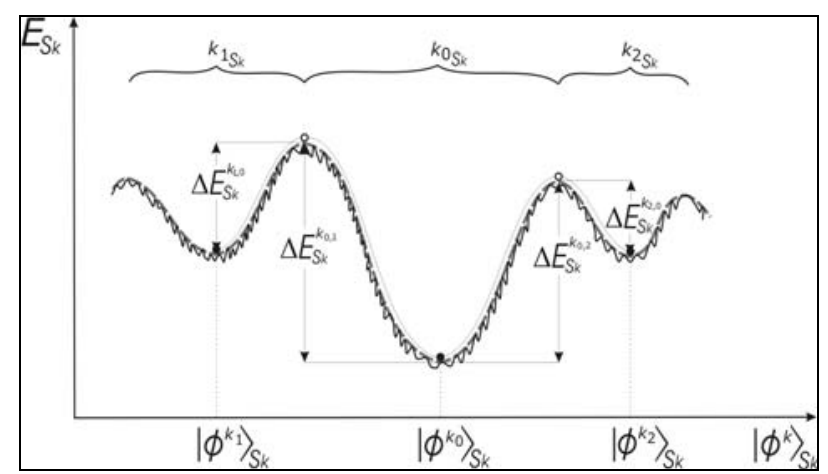

Figure 2. Schematic presentation of the memory attractors in the energy-state $\left(E_{S_{k}}\left(\phi^{k}\right)\right)$ hypersurface of the quantumholographic memory/propagator of the open macroscopic quantum system $S_{k}$ (cell's protein/target biomolecular one $[3,12])$ :

$$
\begin{aligned}
& G\left(r_{2}, t_{2} ; r_{1}, t_{1}\right)=\sum_{i=1}^{P} \phi^{k_{i}}\left(r_{2}, t_{2}\right) \phi^{k_{i}}\left(r_{1}, t_{1}\right) \\
= & \sum_{i=1}^{P} A_{k_{i}}\left(r_{2}, t_{2}\right) A_{k_{i}}{ }^{*}\left(r_{1}, t_{1}\right) e^{\frac{i}{\hbar}\left(\alpha_{k_{i}}\left(r_{2}, t_{2}\right)-\alpha_{k_{i}}\left(r_{1}, t_{1}\right)\right)}
\end{aligned}
$$

It should be pointed out that the quantum decoherence presumably plays a fundamental role in biological quantumholographic neural networks, through presented energy

hypersurface shape adaptation (in contrast to lowtemperature artificial qubit quantum processors where it must be avoided until the very read-out act of quantum computation) - which implies that Nature presumably has

chosen an elegant room-temperature solution for

biological quantum-holographic information processing, permanently fluctuating between quantum-coherent states $\left|\phi^{k}(t)\right\rangle_{S_{k}}=\sum_{i} c_{k_{i}}(t)\left|\phi^{k_{i}}\right\rangle_{S_{k}}$ and classically-reduced states $\hat{\rho}_{S_{k}}^{k}(t)=\sum_{i}\left|c_{k_{i}}(t)\right|^{2}\left|\phi^{k_{i}}\right\rangle_{S_{k} S_{k}}\left\langle\phi^{k_{i}}\right|$ of cell's

biomolecular open macroscopic quantum system $S_{k}$, through nonstationary interactions with farther bodily environment and through decoherence by bodily closer environment. The same might be related to a higher hierarchical quantum-

holographic macroscopic open acupuncture system/ consciousness level thus providing a natural framework for quantum-holographic coupling with lower cellular level, such making a change in the expression of genes. 


\subsection{Resonant Recognition Model}

Resonant Recognition Model $[9,10]$ is confirmed on more than 1000 proteins from over 30 functional groups - with numerous potential practical advantages in the fields of molecular biology, biotechnology, medicine, agriculture and nanotechnology. It is based on findings that there is a significant correlation between spectra of the numerical presentation of constitutive elements of primary sequences (amino acids, nucleotides) and their biological activity or interaction in corresponding biomolecules (proteins, DNAs). The RRM model interprets this linear information by assigning the electron-ion interaction potential (EIIP) value to each constitutive element of primary sequence thus describing their average energy states of valence electrons, with subsequent use of signal analysis methods in fast Fourier transform, transforming this numerical series into single-electron wavenumber/RRM frequency domain and determining the common frequency components as peak frequencies in the multiple crossspectral function for a group of primary sequences. The presence of peak with significant signal-to-noise ratio in a multiple cross-spectral function of a group of sequences with the same biological function means that all the analysed sequences within the group have this single-electron RRM frequency component in common, with the following general conclusions [9]: (1) such a peak exists only for the group of biomolecules with the same function; (2) no significant peak exists for biologically unrelated bio-molecules; (3) peak frequencies are different for different biological function; (4) ligand-proteins and their bio-molecular target-receptors have the same characteristic frequency in common but almost opposite phase providing also novel theoretical possibilities for protein de novo design with desired functions!

In the context of the RRM-model, the same characteristic single-electron RRM frequency, and almost opposite phase, presumably characterises not only biomolecular protein and target general function, but also their quantum biomolecular recognition interaction on the level of biological cell - possibly by externally activated (compositionally/chemically, by averaged intermolecular approaching of proteins and targets necessary for non-vanishing overlap integrals of the corresponding electronic and vibrational wave functions, or thermally/optically, by supplying vibrational energy necessary for making conditions for electronic-vibrational non-radiative resonant transitions between two isomers (i,f), cf. Fig. 1) ligand-proteins/target-receptors RRM quantum-resonantly electron-electron coupling accompanied by $\phi^{(i)}$-annihilation and $\phi^{(f)}$-creation of conformones' quanta in two-conformational transitions $\phi^{(i)} \rightarrow \phi^{(f)}$ (giving rise to (energy-favourable) manyelectron energy-deepening of the final state $\phi^{(f)}$ and many-electron energy-shallowing of the initial state $\phi^{(i)}$ on the macroscopic quantum level of cell, i.e. to dynamic modification of the many-electron hyper-surface $E_{\mathrm{d}}\left(\phi^{(k)}\right)$ of the cell's protein macroscopic quantum system [3,8] (cf. Fig. 2). These transitions are RRM theoretically predicted and experimentally observed in the frequency range of $10^{13}$ to $10^{15} \mathrm{~Hz}$ [14] - which incorporates infrared radiation (when vibrational excitations of ground many-electron hypersurface should be involved), but also visible and a small portion of the ultraviolet radiation (when higher electronic-vibrational excitations of many-electron hypersurface should be involved).

Considered in the framework of Hückel-like theory of molecular orbits $[3,15]$, quantum approach to the RRM-model shows that discrete Fourier transform in the RRM model is basically related to sequential contributions to the first order correction of energy (i.e. primary sequence of amino-residues, but not to (single electron) energy of the periodic part of protein's chain). So, results of the RRM model imply that on the biomolecular level an information processing is going on in the inverse space of Fourier spectra of the primary sequences of biomolecules, bearing resemblance to quantum-holographic ideas that cognitive information processing is going in the inverse space of Fourier spectra of the perceptive stimuli [16], thus supporting the picture of quantumholographic fractal coupling of various hierarchical levels in biological species, with significant potential psychosomatic implications (cf. Fig. 2).

\section{CONCLUSION}

Two unresolved issues of the (semi)classically addressed problems in molecular biophysics are unreasonably long time necessary for change of biopolymer conformations and long-range directedness of selective biomolecular recognition processes implying their essential quantum origin. In this paper several possible quantum approaches are considered: Theory of Non-Radiative Resonant Structural Transitions, through inter-mediate quantum-coherent superposition of the externally activated electronic-vibrational states of the participating biomolecules; Model of Quantum Decoherence, through environment-induced conformational transitions in biomolecular recognition, with possibility to consider cellular biomolecular recognition as a Hopfield-like quantum-holographic associative neural network; 
and Resonant Recognition Model (RRM), based on findings that informational biomolecules and their targets have common RRM-frequency peak but almost opposite phases. These approaches might be of fundamental importance in understanding underlying macroscopic quantum-holographic Hopfield-like control mechanisms of morpho-genesis, and their backward influence on the expression of genes, with significant potential psychosomatic implications.

\section{REFERENCES}

[1] M. V. Volkenshtein, Biophysics, Mir, Moscow 1983.

[2] C. Levinthal, Are there pathways for protein folding? J. Chim. Phys., Vol. 65 (1968) 44-45.

[3] D. Raković, Integrative Biophysics, Quantum Medicine, and Quantum-Holographic Informatics: Psychosomatic-Cognitive Implications, IASC \& IEPSP, Belgrade 2009; D. Raković, Fundamentals of Biophysics, $3^{\text {rd }}$ ed, IASC \& IEFPG, Belgrade 2008, in Serbian; and refs therein.

[4] D. Raković, B. Tošić, S. Jaćimovski, J. Šetrajčić, Biomolecular recognition: On possible quantum approaches, NBP Journal of Criminalistics and Law (Belgrade), Vol. 14 (1) (2009) 33-46.

[5] L. A. Gribov, From Theory of Spectra to Theory of Chemical Transformations, URSS, Moscow 2001, in Russian.

[6] D. Raković, M. Dugić, M. Plavšić, The polymer conformational transitions: A quantum decoherence approach, Mater. Sci. Forum Switzerland, Vols. 453-454 (2004) 521-528; M. Dugić, D. Raković, M. Plavšić, The polymer conformational stability and transitions: A quantum decoherence theory approach, In: A. Spasić, J-P. Hsu (Eds.), "Finely Dispersed Particles: Micro-, Nano-, and Atto-Engineering", CRC Press, New York 2005, 217-232; D. Raković, M. Dugić, M. Plavšić, Biopolymer chain folding and biomolecular recognition: A quantum decoherence theory approach, Mater. Sci. Forum Switzerland, Vol. 494 (2005) 513-518; D. Raković, M. Dugić, M. Plavšić, G. Keković, I. Cosic, D. Davidović, Quantum decoherence and quantum-holographic information processes: From biomolecules to biosystems, Mater. Sci. Forum Switzerland, Vol. 518 (2006) 485-490.

[7] J. Jeknić, M. Dugić, D. Raković, A unified decoherence-based model of microparticles in a solution, Mater. Sci. Forum Switzerland, Vol. 555 (2007) 405-410; J. Jeknić-Dugić, The environment-inducedsuperselection model of the large molecules conformational stability and transitions, Europ. Phys. J. D, Vol. 51 (2009) 193-204; J. Jeknić-Dugić, Decoherence Model of Molecular Conformational Transitions, $\mathrm{PhD}$
Thesis, Faculty of Science, Kragujevac 2010, in Serbian.

[8] D. Raković, Scientific bases of quantumholographic paradigm, Invited lecture. In: I. Kononeko (Ed.), "Proc. Int. Conf. Measuring Energy Fields", Zavod Zdravilni gaj, Kamnik 2007, 64-71; D. Raković, A. Vasić, Classical-neural and quantumholographic informatics: Psychosomatic-cognitive implications, In: B. Reljin, S. Stanković (Eds.), "Proc. NEUREL-2008", IEEE Serbia \& Montenegro Section, Belgrade 2008, 109-114.

[9] I. Cosic, The Resonant Recognition Model of Macro-molecular Bioactivity: Theory and Applications, Birkhauser Verlag, Basel 1997; I. Cosic, Macromolecular bioactivity: Is it resonant interaction between macromolecules? - Theory and applications, IEEE Trans. Biomed. Eng., Vol. 41(12) (1994) 1101-1114; E. Pirogova, M. Akay, I. Cosic, Investigation of the structural and functional relationships of oncogene proteins, Proc. IEEE, Vol. 90(12) (2002) 1859-1867.

[10] V. Veljkovic, A Theoretical Approach to Preselection of Carcinogens and Chemical Carcenogenesis, Gordon \& Breach, New York 1980; V. Veljkovic, M. Slavic, General model of pseudopotentials, Phys. Rev. Lett., Vol. 29 (1972) 105-108.

[11] G. Keković, D. Raković, D. Davidović, Relevance of polaron/soliton-like transport mechanisms in cascade resonant isomeric transitions of Q1D-molecular chains, Mater. Sci. Forum Switzerland, Vol. 555 (2007) 119-124; G. Keković, Nonlinear Excitations of Polymer Structural Transitions, $\mathrm{PhD}$ Thesis, Faculty of Electrical Engineering, Belgrade 2007, in Serbian.

[12] D. Raković, A. Škokljev, D. Djordjević, Introduction to Quantum-Informational Medicine, With Basics of Quantum-Holographic Psychosomatics, Acupunctur-ology and Reflexotherapy, ECPD, Belgrade 2010, in Serbian.

[13] H. Fröhlich, Long-range coherence and energy storage in biological system, Int. J. Quantum Chem., Vol. 2 (1968) 641-649.

[14] V. Vojisavljevic, E. Pirogova, I. Cosic, The effect of electromagnetic radiation $(550-850$ nm) on l-lactatedehydrogenase kinetics, Int. J. Rad. Biol. 83 (4), 221 (2007).

[15] G. Keković, D. Raković, B. Tošić, D. Davidović, I. Cosic, Quantum-mechanical foundations of Resonance Recognition Model, Acta Phys. Polon. A, Vol. 17(5) (2010) 756-759.

[16] K. Pribram, Languages of the Brain: Experimental Paradoxes and Principles in Neuropsychology, Brandon, New York 1971; K. Pribram, Brain and Perception: Holonomy and Structure in Figural Processing, Lawrence Erlbaum, Hillsdale, NJ 1991. 
$\operatorname{son}$

\section{О НЕКИМ КВАНТНИМ ПРИЛАЗИМА БИОМОЛЕКУЛАРНОМ ПРЕПОЗНАВАњУ}

Сажетак: Два отворена питања семи-класично постављених проблема у молекуларној биофизици јесу неразумно дуго време потребно за измену биомолекуларних конформација и дугодометна усмереност селективних процеса биомолекуларног препознавања - имплицирајући њихово суштински квантно порекло. У овом раду је размотрено неколико могућих квантних прилаза биомолекуларном препознавању: теорија нерадијативних резонантних структурних прелаза, модел квантне декохерениије и модел резонантног препознавања. Ови прилази могу бити од фундаменталног значаја за разумевање базичних макроскопских квантно-холографских Хопфилдових контролних механизама морфогенезе и њиховог повратног утицаја на експресију генома, са значајним потенцијалним психосоматским импликацијама.

Кључне речи: Биомолекуларно препознавање, конформациони прелази, квантна биофизика, квантна биоинформатика. 